\title{
Novel Energisation Method for Offshore Wind Farms Connected to HVdc via Diode Rectifiers
}

\author{
Oscar Saborío-Romano $^{(\mathbb{D}}$, Ali Bidadfar ${ }^{(\mathbb{D}}$, Jayachandra N. Sakamuri ${ }^{\mathbb{D}}$, Ömer Göksu ${ }^{(\mathbb{D}}$, Nicolaos A. Cutululis ${ }^{\mathbb{(}}$ \\ Department of Wind Energy \\ Technical University of Denmark \\ Risø Campus, Roskilde, Denmark \\ Email: osro@dtu.dk
}

\begin{abstract}
Recently put forward as a feasible alternative for connecting OWFs to HVdc networks, diode rectifiers (DRs) have elicited growing interest from both academia and industry. Energisation of such OWFs is, however, not straightforward. The present study constitutes a proof of concept for the application of a novel energisation method to the case of an OWF connected to HVdc via DRs. The proposed method provides a robust and reliable alternative with minimal additional hardware, i.e. short additional dc cables connecting the dc bus bar of the energising WT to the HVdc link, and corresponding de disconnectors at the cable terminals and at the DR dc terminals. This can be easily extended to more WTs in the OWF, increasing reliability by providing redundancy. The simulation results indicate that the proposed method is a suitable alternative for energising OWFs connected to HVdc via DRs.
\end{abstract}

Index Terms-Diode-rectifier-based HVdc transmission, energisation, grid-forming wind turbine control, offshore wind energy integration

\section{INTRODUCTION}

Further exploitation of Europe's offshore wind resources entails the development of electrical infrastructure interconnecting offshore wind farms (OWFs) and onshore networks. Thus far, most OWFs are connected via HVac, and only a few export their production through HVdc [1]. The amount of HVdc-connected OWFs, however, is widely expected to increase, as the distance from shore and OWF size increase and the associated costs decrease [2], [3].

Since first presented in 1997 [4], HVdc transmission technology making use of voltage source (forced-/self-commutated) converters (VSCs), based on insulated-gate bipolar transistors, has experienced great development. Such HVdc transmission solutions still have higher losses and overall costs than the more common, mature ones employing (phase-controlled) line-commutated converters, based on thyristors (in a current source converter topology), which are largely used for bulk power transmission [3], [5]. However, VSC-based HVdc transmission (VSC-HVdc) offers advantages such as independent control of active and reactive power, smaller footprints, fast reversibility of active power flow, and the (grid-forming) capability to form ac networks, i.e. to control their ac-side voltage magnitude and frequency (which allows them to operate without the need of a strong AC grid) [4]. Because of such advantages, the use of VSC-based offshore HVdc terminals has enabled the development of HVdc-connected OWFs with the prevailing grid-following approach to controlling wind turbines (WTs), in which WTs rely on other (grid-forming) units (e.g. VSC-based offshore HVdc terminals) forming their ac network [6].

Recently put forward as a feasible alternative for connecting OWFs to HVdc networks, (uncontrolled, line-commutated) diode rectifiers (DRs) have elicited growing interest from both academia and industry [7]-[14]. DR-based offshore HVdc terminals offer advantages such as lower costs, smaller footprints, higher efficiency and higher reliability [9], [13]. As passive devices, however, they are inherently devoid of the grid-forming capability of VSCs. As a consequence, WTs have been suggested as viable candidates to take over such duty. This entails fundamentally different WT and WF controls, changing their control principle from that of grid-following units to that of grid-forming units [7], [12].

\section{A. Wind Farm Energisation}

WTs and WFs have auxiliary systems (loads) that need electricity most of the time, even when the WTs are not generating electricity. Such loads can consist of pitch and yaw motors, oil pumps, air conditioning, dehumidifiers, navigation lights, and measurement, control, protection, communication and safety systems, among others. When WTs generate electricity, a portion of their output is used to supply the energy required by the WF auxiliary loads and offshore ac network. Auxiliary power must otherwise be supplied from local auxiliary energy sources, e.g. batteries or diesel generators or from the networks connected to the WFs [1]. This is the case, for example, when there is no aerodynamic power available from the wind, i.e. the wind speed is below the cut-in wind speed or above the cut-out wind speed of the WTs.

The use of VSC-based offshore HVdc terminals allows remote OWFs to draw the required auxiliary power from the HVdc networks connected to them. This, however, is not possible for OWFs connected to HVdc via DRs or thyristorbased LCCs, as power flows through the former only towards the shore and the latter require a strong (energised) ac network connected to them. Such OWFs thus need to be energised by other means. This is also the case for OWFs connected to HVdc networks via VSCs, when such offshore converters are not operational. 


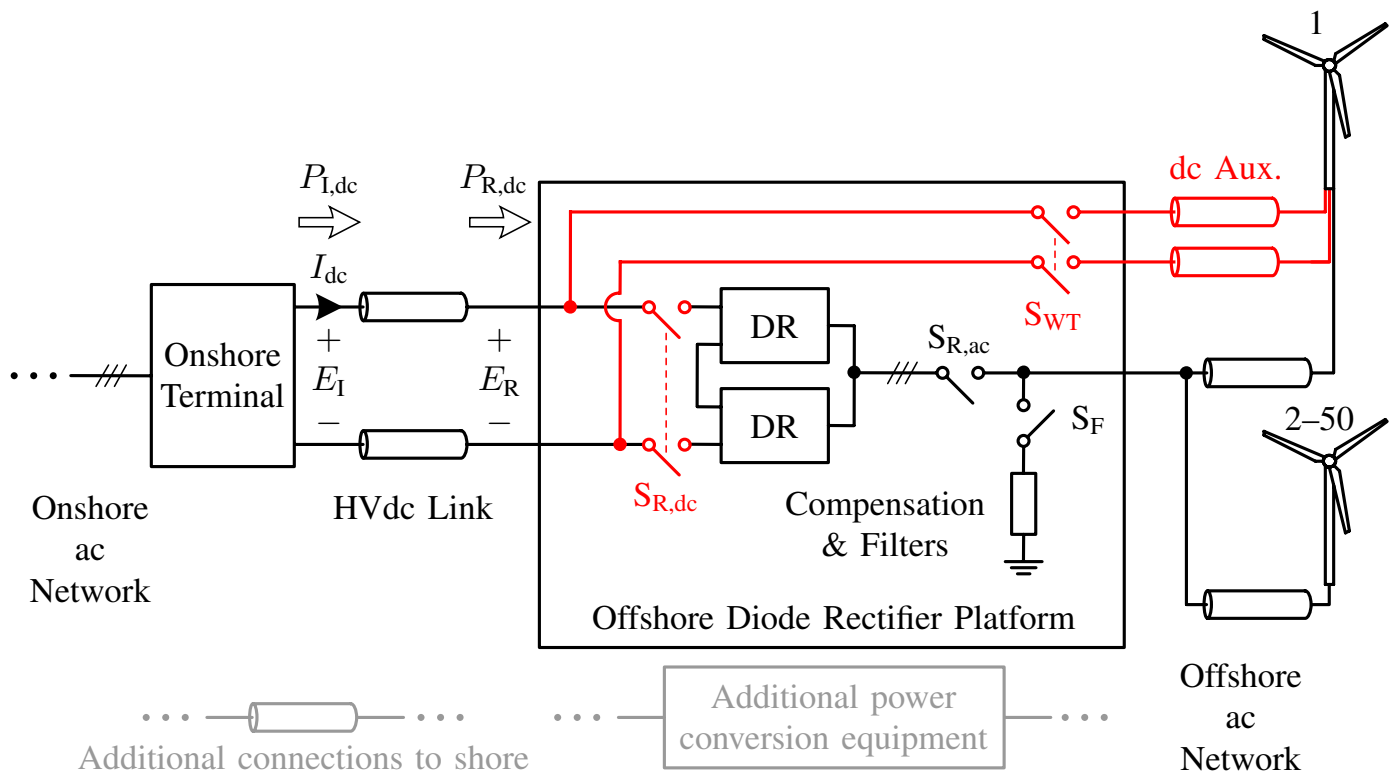

Fig. 1. Overview of the studied system; red: additional equipment introduced by the proposed energisation method, grey: alternatives in literature for providing the auxiliary power from onshore ac networks

Different solutions have been proposed for energising OWFs connected to HVdc via DRs [10], [11], [14]. Solutions for providing the auxiliary power from onshore ac networks are represented in gray in Fig. 1. The use of local auxiliary energy sources or the connection to neighbouring energised offshore ac networks, e.g. other OWFs, have been proposed in [11]. The latter has been considered in several subsequent studies [15], [16].

Additional connections between the OWFs and the onshore ac networks have also been considered. The use of an additional LVdc link has been proposed in [11], which requires additional VSC-based power conversion terminals. Moreover, an additional MVac umbilical cable interconnecting the onshore and offshore ac networks have been introduced in [11]-[14]. Such umbilical cables have been considered in several subsequent studies [15], [17]-[21], and have been assumed to be disconnected during normal operation, i.e. their use has been restricted to the energisation of the corresponding OWFs. Other solutions avoid the need for additional long submarine cables by introducing additional power conversion equipment offshore to effectively bypass the DRs during energisation [10], [11].

In quest of increasing reliability and lowering costs and environmental impact, a new energisation method has been proposed in [22] for OWFs connected to dc networks. The present study constitutes a proof of concept for the application of such method [22] to the case of an OWF connected to an onshore ac network through an HVdc link having a DRbased offshore terminal and a full-bridge-VSC-based onshore terminal. During energisation, the auxiliary power is provided by the onshore ac network through the dc bus bar of one of the WTs. The method only requires short additional dc cables connecting such energising WT dc bus bar to the HVdc link, and corresponding dc disconnectors at the cable terminals and at the DR dc terminals, highlighted in red in Figs. 1 and 2.

The rest of the paper is organised as follows. In Section II, the investigated system is described and the main control algorithms are detailed. In Section III, the considered case is described, and corresponding simulation results are presented and discussed. Finally, concluding remarks are made in Section IV.

\section{Modelling And CONTROL}

Fig. 1 shows an overview of the studied system. The system is based on that described in [15], [18] and consists of one of three $400 \mathrm{MW}$ OWFs connected to an onshore ac network by means of a $200 \mathrm{~km}$ long $1200 \mathrm{MW} \pm 320 \mathrm{kV}$ monopolar HVdc link. Balanced/symmetric operation is assumed. The offshore HVdc terminal: one of three diode rectifier platforms (one per OWF), depicted in Fig. 1, consists of two (uncontrolled, linecommutated) diode-based 12-pulse rectifiers (DRs) connected in series, with corresponding reactive power compensation and filter bank on their ac side.

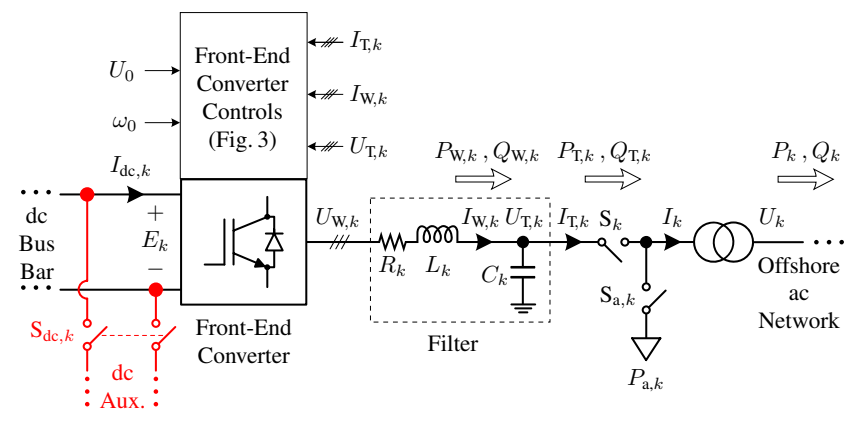

Fig. 2. $\quad k$ th wind turbine front-end (line-side) network; red: additional equipment introduced by the proposed energisation method 


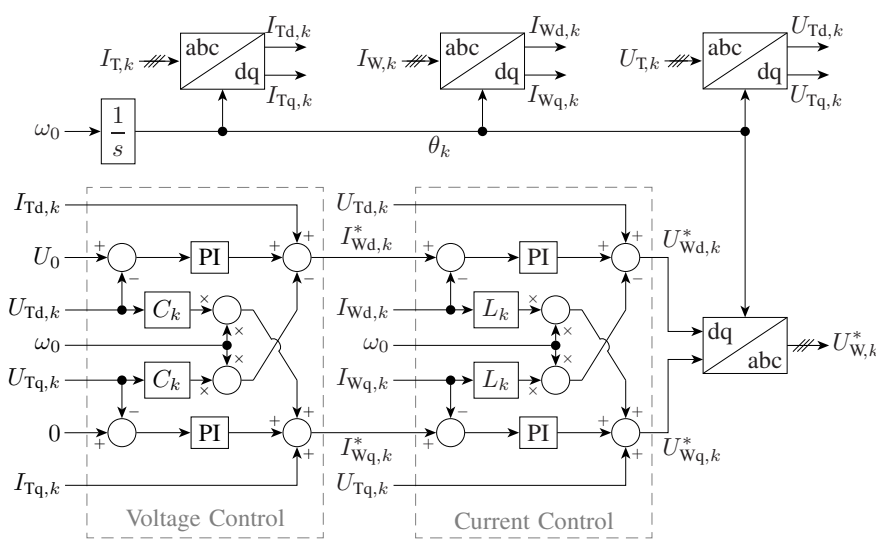

Fig. 3. $k$ th wind turbine front-end (line-side) converter controls

The OWF has 50 type-4 (full-converter) $8 \mathrm{MW}$ WTs. The WT converter nominal ac voltage is $3.3 \mathrm{kV}$. Fig. 2 illustrates the front-end (line-side) network of the $k$ th wind turbine(s), $\mathrm{WT}_{k}$. The auxiliary loads are represented within each (equivalent) WT by a constant active power load, $P_{\mathrm{a}, k}$, corresponding to $0.2 \%$ of the nominal power $(800 \mathrm{~kW}$ in total for the whole WF).

$\mathrm{WT}_{1}$ is chosen as the energising WT: its dc auxiliary supply terminal is connected to that of the DR platform by means of additional dc cables. Additional dc disconnectors are also introduced at the corresponding terminals, $\mathrm{S}_{\mathrm{dc}, 1}, \mathrm{~S}_{\mathrm{WT}}$, and at the DR dc terminals, $S_{R, d c}$. The additional equipment introduced by the method is shown in Figs. 1 and 2, highlighted in red. The HVdc link dynamics are assumed to dominate in the energisation path. The influence of the other elements, e.g, dc cables, effectively interconnecting the $\mathrm{HVdc}$ link and the $\mathrm{WT}_{1}$ dc auxiliary supply terminals (when $\mathrm{S}_{\mathrm{WT}}$ is closed) is thus neglected, i.e. $E_{1} \approx E_{\mathrm{R}}$. The other $49 \mathrm{WTs}$ are aggregated into an equivalent $392 \mathrm{MW} \mathrm{WT}, \mathrm{WT}_{2-50}$, and corresponding cable equivalent $\pi$ circuit using the method proposed in [23]

The WT front-end (line-side) converter (FEC) controls, shown in Fig. 3, are based on those proposed in [24] and consist of cascaded voltage and current control loops, implemented on a rotating reference frame (RRF) with angular speed given by the offshore ac network (angular) frequency set point, $\omega_{0}$, and the quadrature $(\mathrm{q})$ axis leading the direct $(\mathrm{d})$ axis by $90^{\circ}$. The $\mathrm{d}$ axis and $\mathrm{q}$ axis components of the filter capacitor voltage, $U_{\mathrm{T}, k}$, are regulated by the FEC controls to follow the corresponding references, $U_{\mathrm{Td}, k}^{*}, U_{\mathrm{Tq}, k}^{*}$, respectively. The RRF is oriented on $U_{\mathrm{T}, k}$ by setting $U_{\mathrm{Tq}, k}^{*}=0$, whereas $U_{\mathrm{Td}, k}^{*}=U_{0}$ corresponds to the offshore ac network voltage set point.

WT rotor and back-end (generator-side) network dynamics are not considered, as they are not relevant to the case in question. Pulse-width modulation (PWM) is assumed to be done in the linear range, switching effects and any delay due to implementation of the PWM are neglected, and average value models are used to represent the WT FECs. Focus is given to dynamics not faster than the WT FEC (inner/lower) current control loops, which are designed to have a bandwidth of $200 \mathrm{~Hz}$.

The full-bridge-VSC-based onshore HVdc terminal manipulates its dc terminal voltage, $E_{\mathrm{I}}$, according to the openloop control scheme described by (1), in which the estimated voltage drop on the $\mathrm{HVdc}$ link is added to the offshore terminal direct voltage set point, $E_{\mathrm{R}}^{*}$. The voltage drop on the HVdc link is calculated using the onshore terminal current measurement, $I_{\mathrm{dc}}$, and the estimated HVdc link resistance, $\tilde{R}_{\mathrm{dc}}$.

$$
E_{\mathrm{I}}=E_{\mathrm{R}}^{*}+I_{\mathrm{dc}} \tilde{R}_{\mathrm{dc}}
$$

\section{Simulation RESUlTS}

Results of the dynamic simulations performed in PSCAD are presented in Fig. 4. Both (equivalent) WT front-end networks and corresponding converter controls have the same parameter per-unit (pu) values. Moreover, $\omega_{0}=1 \mathrm{pu}$ for both of them. Fig. 4a depicts the voltage at the onshore and offshore ends of the $\mathrm{HVdc}$ link, $E_{\mathrm{I}}$ and $E_{\mathrm{R}}$, respectively, whereas the $\mathrm{HVdc}$ link current, $I_{\mathrm{dc}}$, is shown in Fig. $4 \mathrm{~b}$.

Fig. 4c portrays the rms voltage at the ac terminals of the energising and non-energising (equivalent) WTs, $U_{1}$ and $U_{2-50}$, respectively, at the ac terminals of the energising WT FEC, $U_{\mathrm{W}, 1}$, and at its filter capacitor, $U_{\mathrm{T}, 1}$. The output rms currents of the energising WT, $I_{1}$, and of its FEC filter, $I_{\mathrm{T}, 1}$ are presented in Fig. $4 \mathrm{~d}$, together with the active and reactive components of the latter, $I_{\mathrm{Td}, 1}$ and $-I_{\mathrm{Tq}, 1}$. Fig. 4e portrays the offshore ac network frequency, $f$.

Fig. 4f depicts the active power flowing out of the onshore terminal, $P_{\mathrm{I}, \mathrm{dc}}$, into the offshore diode rectifier platform, $P_{\mathrm{R}, \mathrm{dc}}$, out of the energising WT, $P_{1}$, and into the non-energising (equivalent) WT, $-P_{2-50}$. Finally, the reactive power flowing out of the energising WT FEC, $Q_{\mathrm{W}, 1}$, out of the energising WT FEC filter, $Q_{\mathrm{T}, 1}$, out of the energising WT, $Q_{1}$, and into the non-energising (equivalent) WT, $-Q_{2-50}$, are shown in Fig. $4 \mathrm{~g}$. Table I summarises the simulation sequence of events, which are discussed in the following.

TABLE I

ENERGISATION SEQUENCE

\begin{tabular}{ccl}
\hline Stage & Time [s] & \multicolumn{1}{c}{ Events } \\
\hline 0 & $<0$ & $\begin{array}{l}\text { WTs, offshore ac network and HVdc link de-energised; } \\
\text { voltage set points, } E_{\mathrm{R}}^{*}, U_{0}, \text { set to } 0 ; \text { offshore ac network } \\
\text { (angular) frequency set point, } \omega_{0}, \text { set to } 1 \mathrm{pu} \text {; all ac } \\
\text { circuit breakers and dc disconnectors open }\end{array}$ \\
\hline 1 & 0 & $\begin{array}{l}\text { dc disconnectors } \mathrm{S}_{\mathrm{WT}} \text { and } \mathrm{S}_{\mathrm{dc}, 1} \text { closed: } \mathrm{WT}_{1} \mathrm{dc} \text { bus } \\
\text { bar effectively connected to the HVdc link, } E_{1} \approx E_{\mathrm{R}}\end{array}$ \\
\hline $1-6.39$ & $\begin{array}{l}\text { direct voltage set point, } E_{\mathrm{R}}^{*}, \text { increased from } 0 \text { to the WT } \\
\text { dc bus bar nominal voltage: onshore terminal energises } \\
\text { the HVdc link and } \mathrm{WT}_{1} \text { dc bus bar }\end{array}$ \\
\hline 3 & 9 & $\begin{array}{l}\text { WT } 1 \text { main ac circuit breaker, } \mathrm{S}_{1}, \text { closed } \\
\text { offshore ac network voltage set point, } U_{0}, \text { increased } \\
\text { from } 0 \text { to } 1 \text { pu: } \mathrm{WT}_{1} \text { energises the offshore ac network, } \\
\text { establishing its voltage and frequency }\end{array}$ \\
\hline $30-11$ & $\begin{array}{l}\text { ac circuit breakers } \mathrm{S}_{\mathrm{a}, 1} \text { and } \mathrm{S}_{\mathrm{a}, 2-50} \text { closed: auxiliary } \\
\text { loads energised }\end{array}$ \\
\hline
\end{tabular}



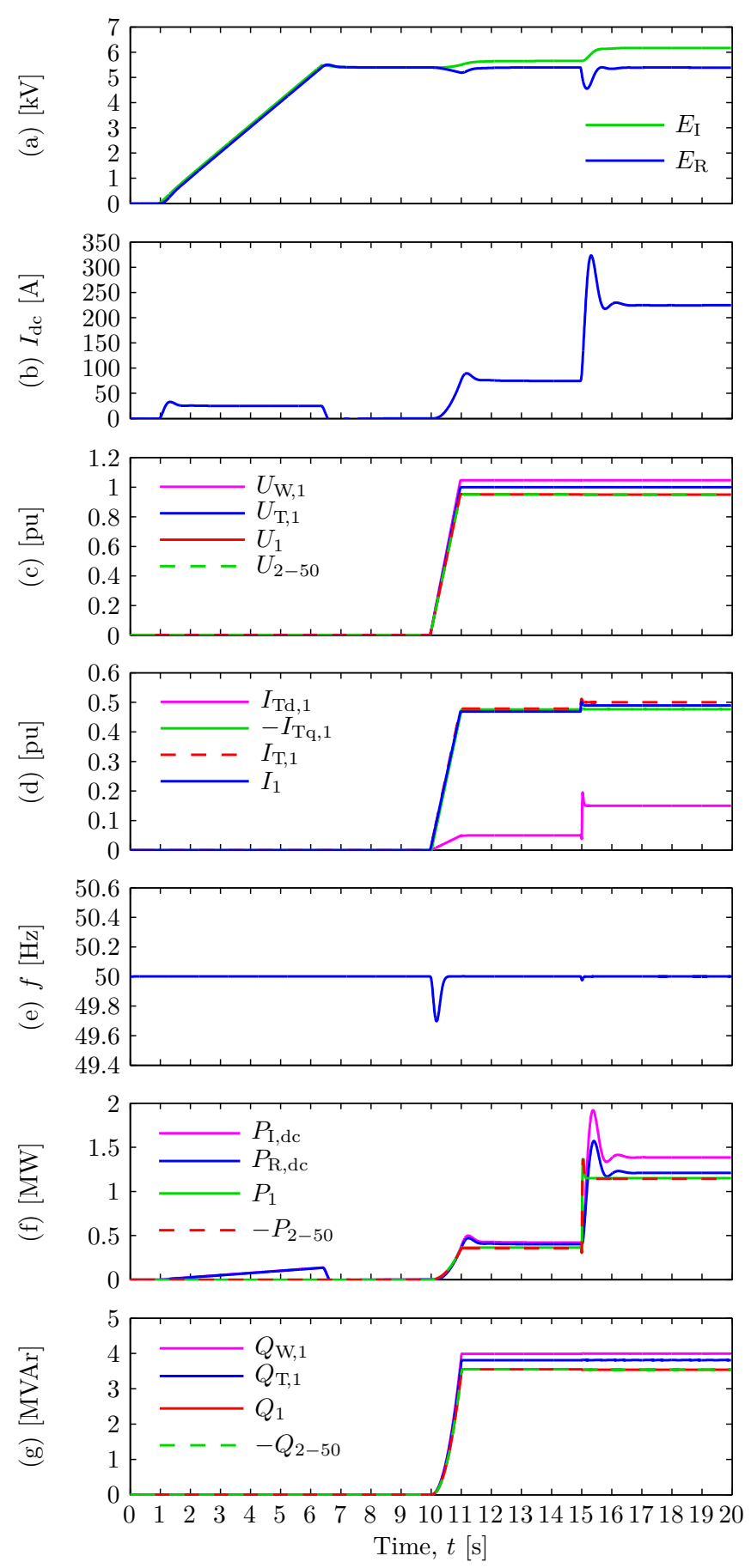

Fig. 4. Simulation results: (a) voltage at the onshore and offshore ends of the $\mathrm{HVdc}$ link, $E_{\mathrm{I}}$ and $E_{\mathrm{R}}$, respectively; (b) HVdc link current; (c) rms voltage at the ac terminals of the energising and non-energising (equivalent) WTs, $U_{1}$ and $U_{2-50}$, respectively, at the ac terminals of the energising WT FEC, $U_{\mathrm{W}, 1}$, and at its filter capacitor, $U_{\mathrm{T}, 1}$; (d) output rms currents of the energising $\mathrm{WT}, I_{1}$, and of its FEC filter, $I_{\mathrm{T}, 1}$, and active and reactive components of the latter, $I_{\mathrm{Td}, 1}$ and $-I_{\mathrm{Tq}, 1}$, respectively; (e) offshore ac network frequency; (f) active power flowing out of the onshore terminal, $P_{\mathrm{Idc}}$, into the offshore diode rectifier platform, $P_{\mathrm{R}, \mathrm{dc}}$, out of the energising WT, $P_{1}$, and into the non-energising (equivalent) WT, $-P_{2-50} ;(\mathrm{g})$ reactive power flowing out of the energising WT FEC, $Q_{\mathrm{W}, 1}$, out of the energising WT FEC filter, $Q_{\mathrm{T}, 1}$, out of the energising WT, $Q_{1}$, and into the non-energising (equivalent) WT, $-Q_{2}-50$

\section{A. Stage 0: Initial Conditions}

Initially, the WTs, offshore ac network and HVdc link are de-energised, the voltage set points, $E_{\mathrm{R}}^{*}, U_{0}$, are set to 0 , and all ac circuit breakers and de disconnectors shown in Figs. 1 and 2 are open.

\section{B. Stage 1: WT dc Bus Bar Energisation}

At $t=0 \mathrm{~s}$, the dc disconnectors $\mathrm{S}_{\mathrm{WT}}$ and $\mathrm{S}_{\mathrm{dc}, 1}$ are closed, effectively connecting the $\mathrm{WT}_{1}$ dc bus bar to the HVdc link, $E_{1} \approx E_{\mathrm{R}}$. Between $t=1 \mathrm{~s}$ and $t=6.39 \mathrm{~s}$, the onshore terminal energises the $\mathrm{HVdc}$ link and $\mathrm{WT}_{1} \mathrm{dc}$ bus bar as the direct voltage set point, $E_{\mathrm{R}}^{*}$, is increased from 0 to the WT dc bus bar nominal voltage (approximately $5.39 \mathrm{kV}$ ), as shown in Fig. 4a. Such rate of increase in the direct voltage (i.e. $1 \mathrm{kV} / \mathrm{s}$ ) requires a temporary charging current of up to 33.1 A, as depicted in Fig. 4b.

\section{Stage 2: Offshore ac Network Energisation}

$\mathrm{WT}_{1}$ main ac circuit breaker, $\mathrm{S}_{1}$, is closed at $t=9 \mathrm{~s}$, and the corresponding FEC then energises the offshore ac network, establishing its voltage and frequency, as the offshore ac network voltage set point, $U_{0}$, is increased from 0 to $1 \mathrm{pu}$ between $t=10 \mathrm{~s}$ and $t=11 \mathrm{~s}$, as illustrated by Figs. 4c and $4 \mathrm{e}$. In doing so, it draws about $422 \mathrm{~kW}$ from the onshore terminal, as depicted by Fig. 4f, which stands for the no-load losses of the studied system. As shown in Figs. $4 \mathrm{a}$ and $4 \mathrm{~b}$, the corresponding increase in dc current causes a temporary drop in the $\mathrm{WT}_{1}$ dc bus bar voltage, $E_{1} \approx E_{\mathrm{R}}$, of about $205 \mathrm{~V}$, i.e. $3.80 \%$ of its nominal value. Moreover, it causes a voltage drop in the HVdc link of about $259 \mathrm{~V} \approx 4.58 \%$ in steady state.

\section{Stage 3: Auxiliary Load Energisation}

Finally, ac circuit breakers $S_{a, 1}$ and $S_{a, 2-50}$ are closed at $t=15 \mathrm{~s}$, and the auxiliary loads are energised, as shown most notably in Fig. 4f. As depicted by Figs. 4a and 4b, the corresponding increase in dc current causes a temporary drop in $E_{1} \approx E_{\mathrm{R}}$, of about $840 \mathrm{~V}$, i.e. $15.6 \%$ of its nominal value. Furthermore, it causes a voltage drop in the HVdc link of about $780 \mathrm{~V} \approx 12.7 \%$ in steady state.

\section{E. Further Comments}

As illustrated by Figs. 4d, 4f and $4 \mathrm{~g}$, reactive (output) current, $-I_{\mathrm{Tq}, 1}$, constitutes most of the energising WT FEC filter output current, $I_{\mathrm{T}, 1}$, in steady state. The corresponding 3.81 MVAr are needed mainly to energise the (equivalent) WT transformers. The active (output) current, $I_{\mathrm{Td}, 1}$, is required to cover the OWF auxiliary loads and active power losses, which constitute $10 \%$ and $5.11 \%$, respectively, of the energising WT's nominal power.

The onshore terminal controller calculates the voltage drop in the HVdc link using the measured $I_{\mathrm{dc}}$ and estimated HVdc link resistance, $\hat{R}_{\mathrm{dc}}$, and compensates for it by increasing $E_{\mathrm{I}}$ accordingly, maintaining $E_{\mathrm{R}}$ close to its reference value, as depicted in Figs. 4a and 4b. $\mathrm{WT}_{1}$ FEC grid-forming controls 
maintain $f$ at $50 \mathrm{~Hz}\left(\omega_{0}=1 \mathrm{pu}\right)$ and regulate $U_{\mathrm{T}, 1}$ to follow $U_{0}$, as depicted by Figs. $4 \mathrm{c}$ and $4 \mathrm{e}$.

As illustrated by Fig. 4d, less than half of the energising WT's nominal rms current is needed to energise the studied OWF with the proposed method. Moreover, it requires an HVdc link current of less than $225 \mathrm{~A}$, i.e. less than $12 \%$ of its nominal current, as shown in Fig. 4b, leaving enough HVdc link current capacity to energise the other two 400 MW OWFs in the same way. In the studied system, such current constitutes the necessary capacity of the additional dc auxiliary supply cables, introduced in the proposed energisation method to interconnect the (also introduced) dc auxiliary supply terminals of the energising WT and of the DR platform. Such capacity can in turn determine the current limit for the corresponding protections.

\section{Conclusions}

The simulation results indicate that the proposed method is a suitable alternative for energising OWFs connected to $\mathrm{HVdc}$ via DRs. With the considered WT converter voltage level, the necessary auxiliary power can be provided to the studied OWF while leaving enough $\mathrm{HVdc}$ link current capacity to energise the other OWFs in the same way. The method provides a robust and reliable alternative with minimal additional hardware, i.e. short additional dc cables connecting the dc bus bar of the energising WT to the HVdc link, and corresponding $\mathrm{dc}$ disconnectors at the cable terminals and at the DR dc terminals. This can be easily extended to more WTs in the OWF, increasing reliability by providing redundancy.

\section{ACKNOWLEDGEMENT}

The authors gratefully acknowledge the contributions of Lorenzo Zeni and Poul E. Sørensen to the discussions leading up to this work. This work has received funding from the European Union's Horizon 2020 research and innovation programme under grant agreement No 691714.

\section{REFERENCES}

[1] CIGRÉ Working Group B3.36, "Special Considerations for AC Collector Systems and Substations Associated with HVDC-Connected Wind Power Plants," Paris, France, Technical Brochure 612, Mar. 2015.

[2] P. Bresesti, W. L. Kling, R. L. Hendriks, and R. Vailati, "HVDC Connection of Offshore Wind Farms to the Transmission System," IEEE Transactions on Energy Conversion, vol. 22, no. 1, pp. 37-43, Feb. 2007.

[3] D. van Hertem, O. Gomis-Bellmunt, and J. Liang, Eds., HVDC Grids: For Offshore and Supergrid of the Future. Hoboken, NJ, United States: John Wiley \& Sons, Mar. 2016.

[4] ABB, "HVDC Light: It's time to connect," Tech. Rep., Mar. 2013. [Online]. Available: http://new.abb.com/docs/default - source/eweadoc/hvdc-light.pdf.

[5] CIGRÉ Working Group B4.37, "VSC Transmission," Paris, France, Technical Brochure 269, Apr. 2005.

[6] CIGRÉ Working Group B4.55, "HVDC Connection of Offshore wind power plant," Paris, France, Technical Brochure 619, May 2015.

[7] R. M. Blasco-Giménez, S. C. Añó-Villalba, J. Rodríguez-D’Derlée, F. Morant-Anglada, and S. I. Bernal-Pérez, "Distributed Voltage and Frequency Control of Offshore Wind Farms Connected With a DiodeBased HVdc Link," IEEE Transactions on Power Electronics, vol. 25, no. 12 , pp. $3095-3105$, Dec. 2010.
[8] R. M. Blasco-Giménez, S. C. Añó-Villalba, J. Rodríguez-D’Derlée, S. I. Bernal-Pérez, and F. Morant-Anglada, "Diode-Based HVdc Link for the Connection of Large Offshore Wind Farms," IEEE Transactions on Energy Conversion, vol. 26, no. 2, pp. 615-626, Mar. 2011.

[9] S. I. Bernal-Pérez, S. C. Añó-Villalba, R. M. Blasco-Giménez, and J. Rodríguez-D'Derlée, "Efficiency and Fault Ride-Through Performance of a Diode-Rectifier- and VSC-Inverter-Based HVDC Link for Offshore Wind Farms," IEEE Transactions on Industrial Electronics, vol. 60, no. 6, pp. 2401-2409, Jun. 2013.

[10] E. V. Larsen, "Electric power transmission system for wind turbine and wind turbine farm and method for operating same," United States Patent Application Publication US 2011/0140511 Al, 16th Jun. 2011.

[11] H. J. Knaak, P. Menke, T. Schröck, R. Schuster, and T. Westerweller, "Wind farm connection having a diode rectifier," International Patent Application Publication WO 2014/131454 A1, 4th Sep. 2014.

[12] T. Christ, S. Seman, and R. Zurowski, "Investigation of DC Converter Nonlinear Interaction with Offshore Wind Power Park System," in Proceedings of the 2015 EWEA Offshore Conference, Copenhagen, Denmark, 10th-12th Mar. 2015.

[13] P. Menke, R. Zurowski, T. Christ, S. Seman, G. Giering, T. Hammer, W. Zink, F. Hacker, D. Imamovic, J. Thisted, P. Brogan, and N. Goldenbaum, "2nd Generation DC Grid Access for Large Scale Offshore Wind Farms," in Proceedings of the 14th Wind Integration Workshop, Brussels, Belgium, 20th-22nd Oct. 2015.

[14] J. Dorn, D. Ergin, T. Hammer, H. J. Knaak, P. Menke, J. Møller, R. Schuster, H. Stiesdal, and J. Thisted, "Converter station with diode rectifier," United States Patent Application Publication US 2016/0013653 Al, 14th Jan. 2016.

[15] PROMOTioN, "Deliverable 3.1: Detailed functional requirements to WPPs," Project Deliverable, Dec. 2016. [Online]. Available: https :// www. promotion - offshore. net/fileadmin/PDFs/D3.1_PROMOTioN_ Deliverable_3.1_Detailed_functional_requirements_to_WPPs.pdf.

[16] - "Deliverable 2.3: Report on simulation results and benchmark," Project Deliverable, 2019, unpublished.

[17] C. Prignitz, H. G. Eckel, S. Achenbach, F. Augsburger, and A. Schön, "FixReF: A control strategy for offshore wind farms with different wind turbine types and diode rectifier HVDC transmission," in Proceedings of the IEEE 7th International Symposium on Power Electronics for Distributed Generation Systems (PEDG 2016), Vancouver, BC, Canada, 27th-30th Jun. 2016.

[18] PROMOTioN, "Deliverable 3.2: Specifications of the control strategies and the simulation test cases," Project Deliverable, Mar. 2017. [Online]. Available: https://www.promotion-offshore.net/fileadmin/PDFs/D3.2_ Specifications_Control_strategies_and_simulation_test_cases.pdf.

[19] C. Neumann, H.-G. Eckel, S. Achenbach, and F. Augsburger, "Auxiliary Power Supply in a FixReF Controlled Offshore Wind Power Plant with Diode Rectifier HVDC Transmission," in Proceedings of the 16th Wind Integration Workshop, Berlin, Germany, 25th-27th Oct. 2017.

[20] PROMOTioN, "Deliverable 3.4: Results on control strategies of WPPs connected to DR-HVDC," Project Deliverable, Jan. 2018. [Online]. Available: https://www. promotion - offshore . net/fileadmin/PDFs/D3 . 4_PROMOTioN_Results_on_control_strategies_of_WPPs_connected_ to_DR-HVDC.pdf.

[21] R. Ramachandran, S. Poullain, A. Benchaib, S. Bacha, and B. Francois, "AC Grid Forming by Coordinated Control of Offshore Wind Farm connected to Diode Rectifier based HVDC Link - Review and Assessment of Solutions," in Proceedings of the 20th European Conference on Power Electronics and Applications (EPE 2018 - ECCE Europe), Riga, Latvia, 17th-21st Sep. 2018.

[22] A. Bidadfar, O. Saborío-Romano, P. E. Sørensen, N. A. Cutululis, M. Altin, and Ö. Göksu, "System and method for energising an AC network of an offshore wind farm," European Patent Application EP 18204886.8, 7th Nov. 2018.

[23] E. Muljadi, S. Pasupulati, A. Ellis, and D. Kosterov, "Method of Equivalencing for a Large Wind Power Plant with Multiple Turbine Representation," in Proceedings of the IEEE PES 2008 General Meeting, Pittsburgh, PA, United States, 20th-24th Jul. 2008.

[24] A. Yazdani, "Control of An Islanded Distributed Energy Resource Unit with Load Compensating Feed-Forward," in Proceedings of the IEEE PES 2008 General Meeting, Pittsburgh, PA, United States, 20th-24th Jul. 2008. 